\title{
If I could talk to the animals
}

Review of Gregory Radick: The simian tongue: The long debate about animal language. Chicago: The University of Chicago Press, 2007, 578pp, \$45.00 HB

\section{Colin Allen}

Greg Radick's The Simian Tongue is a superb book. But because it is in the nature of academic reviewing to find something to prod the author about, I will focus on one of his featured conclusions. Near the beginning of his final chapter he writes, "So twice, following two quite different paths, history generated the primate playback experiment" (366). Near the end of the chapter, he comes back to this theme, writing, "the book has sought to explain how the primate playback experiment, as publicly important science, came to be invented when it was, how it came to disappear when it did, and how it came to be reinvented when it was" (378-379). Eight decades after Richard Garner was thwarted in his paln to take a phonograph to Gabon, Robert Seyfarth and Dorothy Cheney went to Kenya to study vervet monkeys with recording equipment in tow. It is true that their plans overlapped insofar as these entailed recording the vocalizations of their simian subjects and playing them back in order to observe the primates' responses. But in what sense were these two expeditions aimed at carrying out the same experiment? Indeed, to what extent is there such a thing as the primate playback experiment?

Garner's 1893 activities at the fringes of the St. Anne's mission are shrouded in mystery and controversy. Radick is sympathetic to Garner's defense against the explicit charges of fraud that were leveled against him. But regardless of whether he left bills unpaid or fired his rifle at gorillas, the fact is that Garner managed to do little by way of producing actual scientific results. Conwy Lloyd Morgan, whom Radick portrays as eagerly awaiting Garner's return from the Congo, eventually came to regard Garner as, Radick writes, "a tender-minded amateur" (86). For Morgan, who in the 1890s was at the forefront of rejecting George Romanes's anecdotal approach and urging the adoption of more rigorous experimental methods among comparative psychologists, the disappointment must have been acute. So, what went wrong? Did Garner have a good idea for an experiment, but poor execution? Or was he a rank amateur even in the business of experimental design?

Radick's discussion of Garner's methods does not fully enlighten. In the section of chapter three titled "A Closer Look at Garner's Experiment and Theoretical Programme", there is a page-long description by a journalist who observed Garner at work in New York's Central Park Zoo in 1891, mostly detailing the difficulties of positioning the phonograph's horn so as to get a clear recording of the monkeys (a term that in the writings of the day seems sometimes also to refer to apes). Radick also describes Garner's interactions with freshly arrived contingent of rhesus macaques: 'When Garner recorded the local word for 'salutations' and repeated it to the new monkeys, their excited response showed, he believed that the word was their word too" (99). Did Garner attempt any experimental controls to support this belief? Since this was their first experience with the playback, would other sounds have produced the 
same degree of excitement? We will never know. Contrast this with the long excerpt of the letter from Seyfarth and Cheney sent to their postdoctoral advisor Peter Marler in late 1977, where controls for playback experiments are explicitly discussed (350). Furthermore, the Kenyan experiments were undertaken against a backdrop of information about the functional significance of various calls made by vervet monkeys that had been gathered in the field by Marler's former student, Thomas Struhsaker. Where Garner's 'experiments' seem rather like a fishing expedition, Cheney and Seyfarth designed their experiments with specific questions in mind.

Undoubtedly Radick is right that the conditions and equipment available to Seyfarth and Cheney were a major factor in the success of their experiments. The nineteenth century phonograph made successful recording and playback difficult enough in a major metropolitan zoo and was practically doomed to fail in a cage on the edge of the forest in Africa. Directional microphones, and speakers small enough to be hidden in the bushes, along with a greater understanding of the role that distance plays in different communicative interactions (338), all favored the efforts in the late 1970s. But still, I think we should not ignore the development of the controlled experiment under natural or naturalistic conditions as a kind of technological development that also separates Garner from the ethologists of the late twentieth Century.

There's a distinction here between experimental technique and experimental design. Garner had a very clever idea, to use recording equipment to capture and then measure the responses of animals to their own vocalizations. But even had the equipment been up to standards of the transistor age, it is far from clear that he would have known what to do with it. In discussing influences on Marler, Radick refers to J. Bruce Falls's work on playback experiments in the 1960s with captive birds and artificially modified songs as "a kind of acoustic updating of what Lack had done with a stuffed robin and Tinbergen with cardboard hawks" (303). And although Marler, Seyfarth, and Cheney eschewed the use of synthesized vocaliza- tions in their field work, they were nevertheless the beneficiaries of the Tinbergenian development of an experimental tradition in ethology. By the 1960s, there were ideas in the air about what to do with playbacks, of which Garner could not be a beneficiary. And in the three decades since the initial success of Marler, Cheney, and Seyfarth, the field playback technique has been widely copied for many different experiments upon a wide range of primate and non-primate subjects. Not one playback experiment, but many.

"We have seen", Radick writes in his final paragraph, "what the experiment- guided exploration of the meaning of primate vocalizations meant for Garner, his contemporaries, and his successors, with these meanings recuperated through reconstruction of contexts from Darwin to Chomsky (and Chimpsky), down to the vervet research of Marler, Cheney, and Seyfarth" (380). He continues, "The primate playback that in Garner's hands revealed evolution's hierarchies under- mined them in Marler's, Cheney's, and Seyfarth's hands" (ibid.). Well, yes, they drew very different lessons, but from what? Not from the same experiments, I would argue-nor even may it be accurate to describe Garner's work as "experiment- guided explorations". And while it may seem churlish to ask for more from such a rich book as Radick has provided, I 
would like to urge future historians and philosophers of ethology to give experiments and their multiple roles the kind of attention that has been afforded to other disciplines by historians and philosophers of experimentation. 